\title{
Desain Instalasi Listrik Bangunan Bertingkat (Studi Kasus: Pesantren Khoiru Ummah Sumedang)
}

\section{Ibnu Hajar'; Dhami Johar Damiri²; Yuliansyah ${ }^{3}$; Jumiati ${ }^{4}$; M. Syair Pandu Lesmana ${ }^{5}$; Muhammad Iqbal Romadhoni ${ }^{6}$}

\author{
1, 2, 3, 4, 5, 6 Intitut Teknologi PLN
}

1ibnu.hajar@itpln.ac.id

\begin{abstract}
The electrical installation is a circuit of electrical equipment which is interconnected with one another and it is within the scope of the electrical power system. This article is to present the result of social community service (PkM) activity at Boarding School of STP SMP/SMA KU Sumedang, that shows an electrical installation design of multi-storey building. In construction of multi-storey building of this boarding school, they do not have an electrical installation design. So, the design in this article is to provide design drawings of the electrical installation, so it could be guidance of setting up of electrical installation for the new boarding school building. So that, they got the electrical installation safely for human and the equipment, as well reliable and comfort during using electricity. The design drawings that resulted from the social community service are drawings of front look, beside look, wiring, and single line diagram (SLD). Also, resulted total power calculation, protection, and capacity (rating) of MCB, and calculated cable rating (KHA), choosing type and cross-sectional area of cables that will be used in electrical installation design for the boarding school building.
\end{abstract}

Keywords: Electrical installation, multi-storey building, design drawing

\begin{abstract}
ABSTRAK
Instalasi listrik merupakan suatu rangkaian peralatan-peralatan listrik yang saling berhubungan antar satu dengan yang lain, dan berada dalam satu lingkup sistem ketenagalistrikan. Artikel ini mempresentasikan hasil kegiatan pengabdian pada masyarakat (PkM) di Pondok Pesantren STP SMP/SMA KU Sumedang yang menunjukkan desain instalasi listrik bangunan bertingkat. Dalam pembangunan gedung bertingkat pondok pesantren ini, mereka tidak memiliki perencanaan (desain) instalasi listrik. Karena itu, desain pada artikel ini bertujuan untuk menyiapkan gambar desain instalasi listrik, sehingga dapat menjadi panduan pemasangan instalasi listrik pada bangunan pesantren tersebut. Agar mereka mendapatkan instalasi listrik yang aman bagi manusia dan peralatan, juga handal dan nyaman selama menggunakan listrik. Gambar desain yang dihasilkan pada kegiatan ini adalah gambar tampak depan, tampak samping, gambar pengkawatan, dan single line diagram (SLD). Dan juga dihasilkan perhitungan daya total, kapasistas pembatas dan pengaman (MCB), serta perhitungan nilai KHA kabel, memilih jenis kabel dan luas penampang yang digunakan dalam rencana instalasi listrik pada bangunan ponpes.
\end{abstract}

Kata kunci: Instalasi listrik, bangunan bertingkat, gambar rencana (desain) 


\section{PENDAHULUAN}

Instalasi listrik merupakan suatu rangkaian dari peralatan listrik yang saling berhubungan antar satu dengan yang lain, dan berada dalam satu lingkup sistem ketenagalistrikan. Instalasi listrik yang baik adalah instalasi yang aman bagi manusia dan akrab dengan lingkungan sekitarnya [1]. Mengingat pula bahwa listrik dapat pula membahayakan manusia dan dapat menimbulkan dampak negativ terhadap lingkungan, maka selalu diupayakan agar tenaga listrik yang didistribusikan dapat dilaksanakan secara [1]: (a) Aman bagi manusia dan peralatan, dan (b) Handal dalam arti mampu menyalurkan energi listrik dengan baik bagi konsumen.

Ada beberapa hal yang perlu diperhitungkan dalam cara pemasangan instalasi listrik pada bangunan gedung seperti jarak antar titik listrik ke titik listrik lainnya, komponen / peralatan listrik yang dipakai, pembagian daya yang harus disesuaikan dengan kebutuhan ruangannya masingmasing, dan sebagainya. Bila semua itu dilakukan dengan cara yang tepat, maka hasilnyapun akan dirasakan langsung, yaitu kondisi aman dan nyaman selama menggunakan listrik [1], karena itu dalam sebuah pekerjaan pemasangan instalasi listrik rumah tinggal atau bangunan gedung bertingkat, dibutuhkan sebuah perencanaan yang matang untuk dapat melaksanakan pemasangan instalasi listrik yang baik dan benar [2].

Suatu instalasi penerangan dapat berfungsi dengan baik dan aman haruslah memenuhi syarat pemilihan pengaman dan penghantar. Faktor-faktor yang harus diperhatikan di dalam merencanakan suatu instalasi penerangan listrik adalah confort (kenyamanan); berhubungan tingkat pencahayaan pada berbagai fungsi ruangan, estetika (keindahan); berhubungan dengan jenis warna dan kekuatan penerangan, dan memenuhi syarat-syarat teknis [3].

Dalam merancang instalasi penerangan kita harus membuat berkas rancangan yang terdiri dari: gambar situasi, gambar instalasi, gambar diagram garis tunggal, dan gambar rinci. Dan selain itu, dalam merancang instalasi penerangan harus menentukan tata letak lampu dan pembagian beban, menentukan banyak kelompok penerangan, menentukan keseimbangan beban, menentukan ukuran sekring/MCB (pengaman) dan penghantar dan juga harus mengetahui komponen-komponen yang digunakan untuk memasang instalasi penerangan [3].

Pesantren yang menjadi tempat pelaksanaan pengabdian kepada masyarakat $(\mathrm{PkM})$ ini sedang membangun gedung bertingkat tiga lantai namun dalam pembangunannya tidak memiliki perencanaan (desain), baik perencanaan sipil (konstruksi) maupun perencanaan instalasi listrik. Sehingga bangunan ini dikerjakan dengan tidak menggunakan gambar perencanaan. Karena itu, dengan permasalahan yang ada pada mitra maka target yang akan dicapai pada kegiatan PkM ini adalah adanya dena gambar bangunan dan gambar instalasi listrik (routing cable, single line diagram (SLD)) yang sesuai dengan persyaratan yang ditetapkan yaitu PUIL 2011 dan dapat dijadikan acuan bagi mitra untuk memasang instalasi listrik yang benar dan baik.

\section{METODE}

Instalasi listrik dalam suatu bangunan harus memenuhi persyaratan yang ditetapkan karena seharusnya setiap instalasi listrik yang terpasang pada pelanggang (instalasi pemanfaatan tenaga listrik / instalasi pelanggan) harus melalui pemeriksaan oleh suatu lembaga independen yaitu Lembaga Pemeriksa Kesesuaian Standar PUIL. Instalasi listrik yang baru terpasang tidak bisa dioperasikan sebelum mendapatkan izin pengoperasian dari lembaga pemeriksa kesesuaian standar PUIL.

PUIL memberikan persyaratan untuk desain, pemasangan dan verifikasi instalasi listrik. Persyaratan ini dimaksudkan untuk menetapkan keselamatan manusia, ternak, dan harta benda 
terhadap bahaya dan kerusakan yang dapat timbul pada pemakaian secara wajar instalasi listrik dan untuk menetapkan fungsi yang tepat dari instalasi tersebut [4].

Berdasarkan permasalahan yang dihadapi oleh mitra, pengelolah pesantren STP SMP/SMA KU Sumedang yaitu bahwa mereka tidak memiliki gambar rencana dalam pembangunan gedung pesantren tersebut, baik gambar sipil/arsitek, mekanikal, maupun elektrikal. Oleh karena itu, dalam menyelesaikan permasalahan tersebut, team PkM mengambil peran sebagai perencana khusus untuk perencanaan sistem elektrikalnya.

Metode pelaksanaan untuk menyelesaikan permasalahan tersebut adalah team PkM membuat gambar rancangan dan perhitungan. Gambar rancangan yang dihasilkan pada kegiatan ini adalah gambar tampak, gambar wiring, dan gambar single line diagram (SLD). Sedangkan perhitungannya adalah perhitungan daya dan kapasitas pengaman (MCB), serta kuat hantar arus (KHA) kabel. Berikut dijelaskan secara detail gambar rencana dan perhitungan yang dihasilkan dalam kegiatan ini.

\subsection{Gambar Rencana Instalasi Listrik}

Dalam pemasangan suatu instalasi listrik, membuat gambar rencana kelistrikan adalah harus dilakukan terlebih dahulu dan gambar rencana tersebut harus didasarkan pada denah bangunan dimana instalasi listrik akan diinstal. Dari gambar rencana kelistrikan tergambar pembagian beban dan jenis kabel serta luas penampang kabel yang akan digunakan. Spesifikasi setiap peralatan dan syarat-syarat yang harus diikuti dalam suatu pekerjaan instalasi tercantum dalam suatu gambar rencana instalasi listrik [5].

Gambar-gambar yang dibutuhkan dalam suatu rancangan instalasi listrik adalah

a. Layout atau gambar situasi bangunan, yaitu gambar rencana dimana bangunan tersebut berada. Layout ini menggambarkan arah angin dan posisi bangunan diantara bangunanbangunan (gedung-gedung) yang berada disekitarnya.

b. Gambar tampak, yaitu gambar rencana yang menunjukkan dari mana gambar rencana tersebut dilihat. Gambar tampak ini menvisualisasi bangunan bila dilihat dari depan, samping, dan atas dan diistilahkan sebagai gambar tampak depan, tampak samping dan tampak atas.

c. Layout peralatan yaitu gambar rencana penempatan peralatan-peralatan listrik yang akan dipasang dan sarana-sarana pelayanannya, seperti titik lampu, saklar, kotak kontak (stop kontak), perlengkapan hubung bagi (PHB).

d. Routing cable atau gambar instalasi yaitu gambar rencana jalan/rute kabel dari $\mathrm{kWh}$ meter, PHB ke peralatan-peralatan listrik dan sarana-sarana pelayanannya.

e. Gambar wiring atau pengkawatan, yaitu gambar rencana penyambungan peralatan listrik dengan sarana-sarana pelayanannya,

f. Single line diagram (SLD) atau Diagram satu garis, yaitu gambar rencana yang menggambarkan diagram perlengkapan hubung bagig dengan keterangan mengenai ukuran atau daya nominal setiap komponen, gambaran kuat arus dan jenis pengaman yang akan digunakan, jenis kabel dan luas penampangnya, keterangan beban terpasang dan pembagiannya, dan sistem pentanahannya.

g. Detail drawing atau gambar detail, yaitu gambar yang menunjukkan detail suatu peralatan seperti dimensi PHB, juga cara pemasangan alat-alat listrik dan cara pemasangan kabel dan cara kerja instalasi kontrolnya.

Namun pada jurnal PkM ini tidak semua gambar desain yang dijelaskan di atas akan ditampilkan. 


\subsection{Perhitungan Daya dan Kapasitas Pengaman}

Instalasi listrik gedung/bangunan bertingkat tidak berbeda dengan instalasi rumah/gedung/bangunan yang tidak bertingkat, hanya saja instalasi bangunan bertingkat tentu lebih banyak menggunakan peralatan-peralatan listrik seperti titik-titik lampu yang lebih banyak, dan bangunan bertingkat juga perlu menambah pengaman (PHB) disetiap lantai untuk melayani peralatan-peralatan listrik untuk lantai tersebut.

Perhitungan daya harus dilakukan dengan hati-hati agar tidak salah memilih/memasang pengaman MCB dan juga dapat menentukan luas penampang kabel yang akan digunakan. Perhitung daya dapat dihitung berdasarkan persamaan-persamaan daya berikut:

$$
\begin{aligned}
& P=V I \cos \varphi \\
& Q=V I \sin \varphi \\
& S=V I \quad \text { atau } \\
& S=\sqrt{P^{2}+S^{2}} \\
& \mathrm{P} \quad=\text { daya aktif (Watt) } \\
& \mathrm{Q} \text { = daya reaktif (VAR) } \\
& \mathrm{S} \text { = daya semu (VA) } \\
& \mathrm{V} \quad=\text { tegangan (Volt) } \\
& \mathrm{I}=\text { Arus (Amper) } \\
& \cos \varphi=\text { factor daya }
\end{aligned}
$$

Total daya yang terpasang pada suatu bangunan dapat dihitung dengan menjumlahkan seluruh daya yang terpasang pada bangunan tersebut. Dengan mengetahui total daya yang terpasang pada suatu bangunan maka selanjutnya adalah menentukan kapasitas pengaman atau pembatas MCB yang akan dipasang dengan menggunakan persamaan-persamaan daya tersebut di atas.

Sedangkan luas penampang kabel dapat diperolah dengan menghitung kuat hantar arus (KHA) kabel dengan cara arus nominal beban yang terpasang pada satu jalur kabel yang digunakan untuk melayani beban-beban tersebut dan dikalikan dengan $125 \%$, seperti persamaan berikut:

$$
K H A=1,25 \times I_{n}
$$

Dimana:

$$
\begin{aligned}
& \text { KHA }=\text { Kuat hantar arus (Amper) } \\
& I_{n} \quad=\text { Arus nominal beban (Amper) }
\end{aligned}
$$

Dengan mendapatkan nilai KHA, maka luas penampang kabel dapat diperoleh dari tabel nilai KHA yang tersedia pada PUIL.

\section{HASIL DAN PEMBAHASAN}

Pada kegiatan ini menghasilkan beberapa gambar desain yang akan bisa menjadi acuan bagi pengelola Pondok Pesantren STP SMP/SMA KU Sumedang untuk memasang instalasi listrik pada bangunan yang sedang dibangun. Pada bangunan ini terdiri dari 3 lantai dan masing-masing lantai terdiri dari 5 ruang kelas/kantor. Gambar 1 berikut adalah gambar denah lokasi bangunan baru Ponpes STP SMP/SMA KU Sumedang. Gambar 2 dan Gambar 3 menunjukkan gambar rencana 
instalasi listrik bangunan baru yang apabila dilihat dari depan dan samping (tampak depan dan tampak samping.

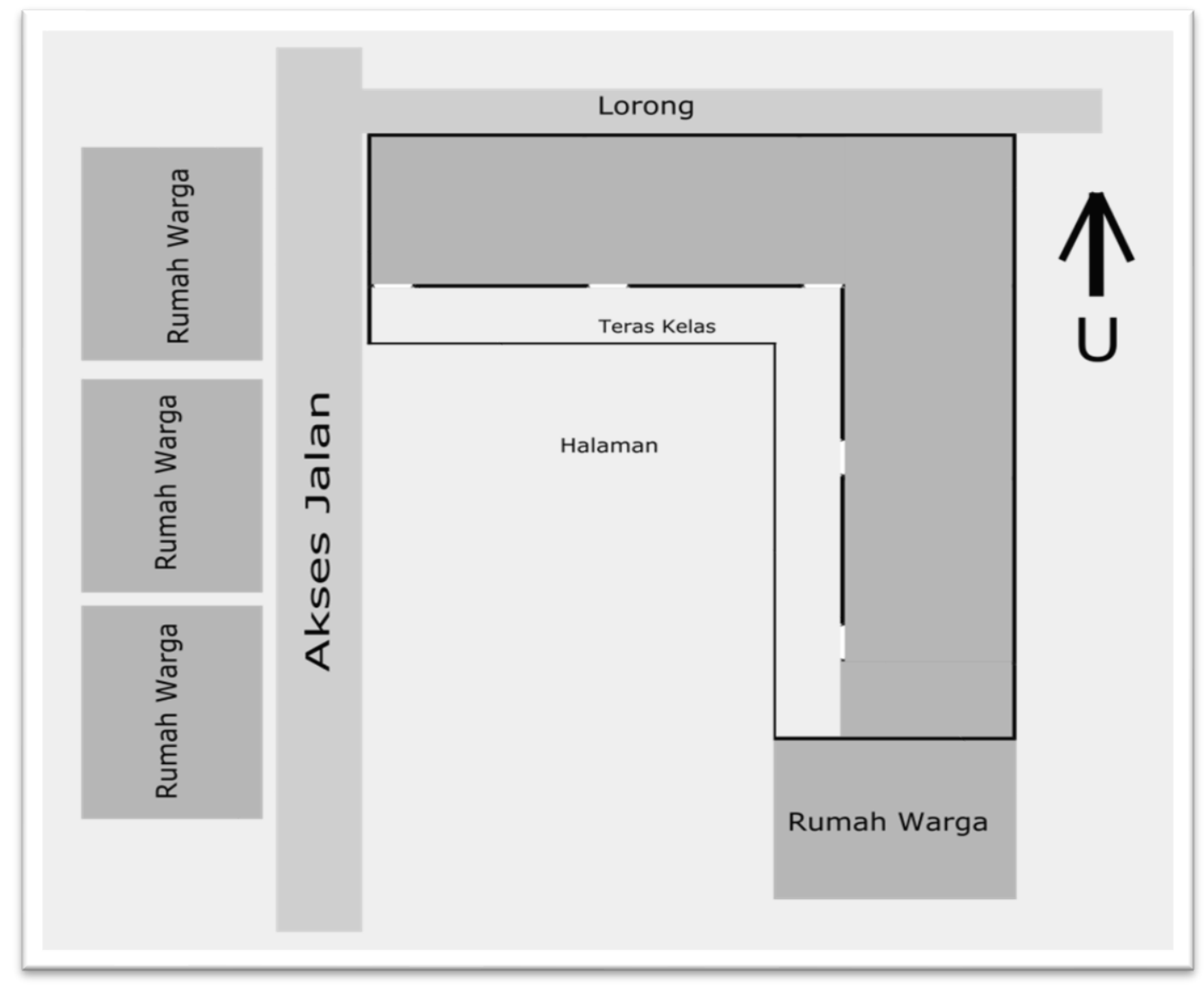

Gambar 1. Denah Bangunan Baru Ponpes STP SMP/SMA KU Sumedang

Gambar rencana pengkawatan diberikan dalam Gambar 4. Gambar ini menunjukan hubunganhubungan antara titik-titik lampu dengan saklarnya, dan juga digambarkan kotak kontak dan papan/panel hubung bagi (PHB). Masing-masing lantai memiliki gambar pengkawatan yang sama karena desain ruang kelas setiap lantai sama, karena itu gambar pengkawatan yang diberikan disini hanya 1 gambar pengkawatan yang mewakili gambar pengkawatan untuk setiap lantai.

Titik-titik lampu yang dirancang di dalam kelas terdiri dari 4 lampu LED dalam satu kelas dengan daya setiap lampu adalah 12Watt setara dengan 98Watt lampu biasa. Penentuan 4 titik lampu dalam satu kelas dengan luas ruang kelas 4 x $5 \mathrm{~m}^{2}$ telah dihitung berdasarkan perhitungan lumen yaitu untuk ruang kelas menggunakan iluminasi 250 lux. Perhitungan kekuatan cahaya dengan metode lumen ini akan dibahas lebih lanjut dalam jurnal berikutnya yaitu Perancangan Jumlah dan Tata Letak Titik Lampu Ruang Kelas Pada Pondok Pesantren STP SMP/SMA KU Sumedang Dengan Metode Perhitungan Lumen. 


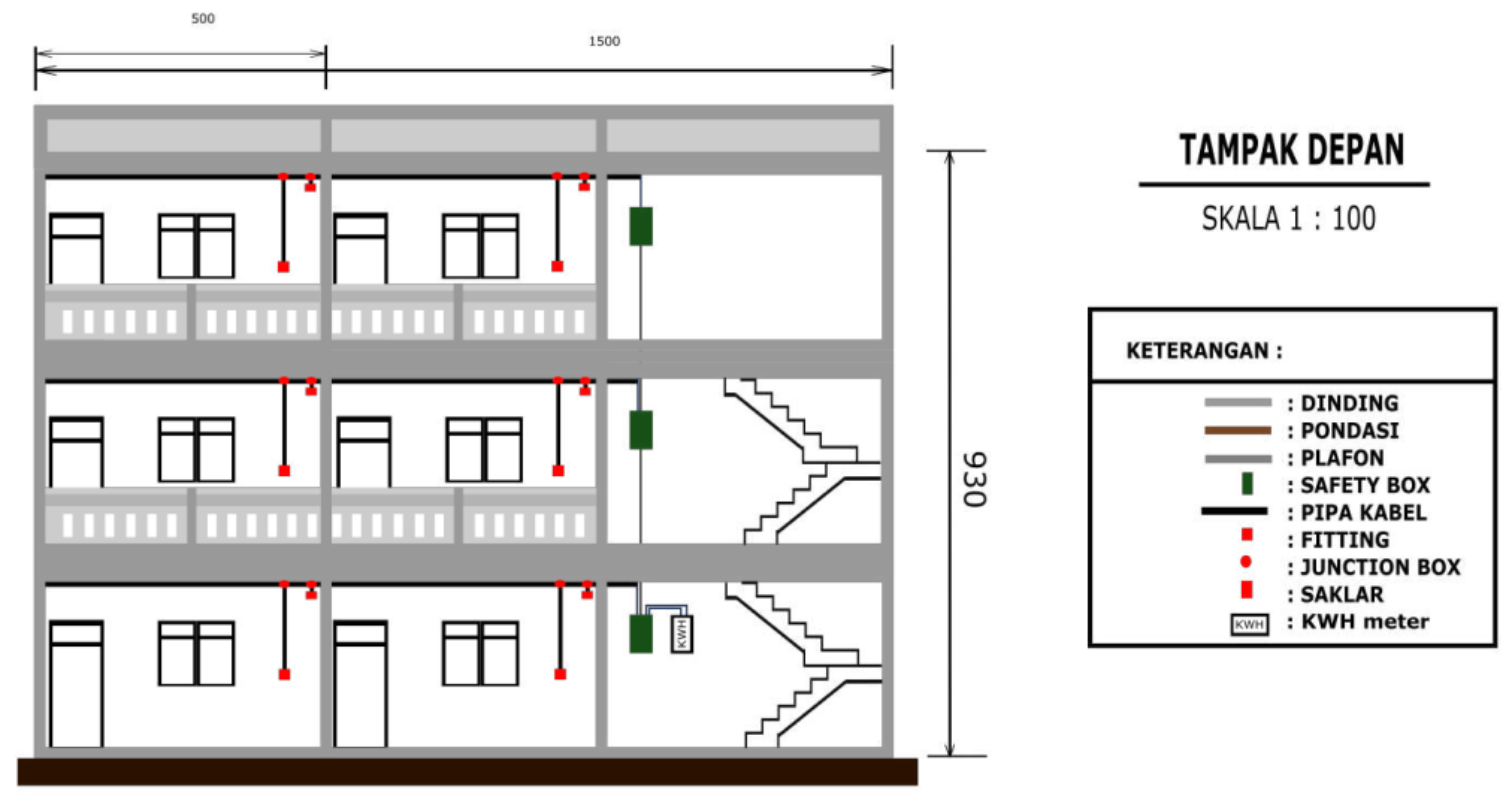

Gambar 2. Tampak Depan Bangunan Baru Ponpes STP SMP/SMA KU Sumedang

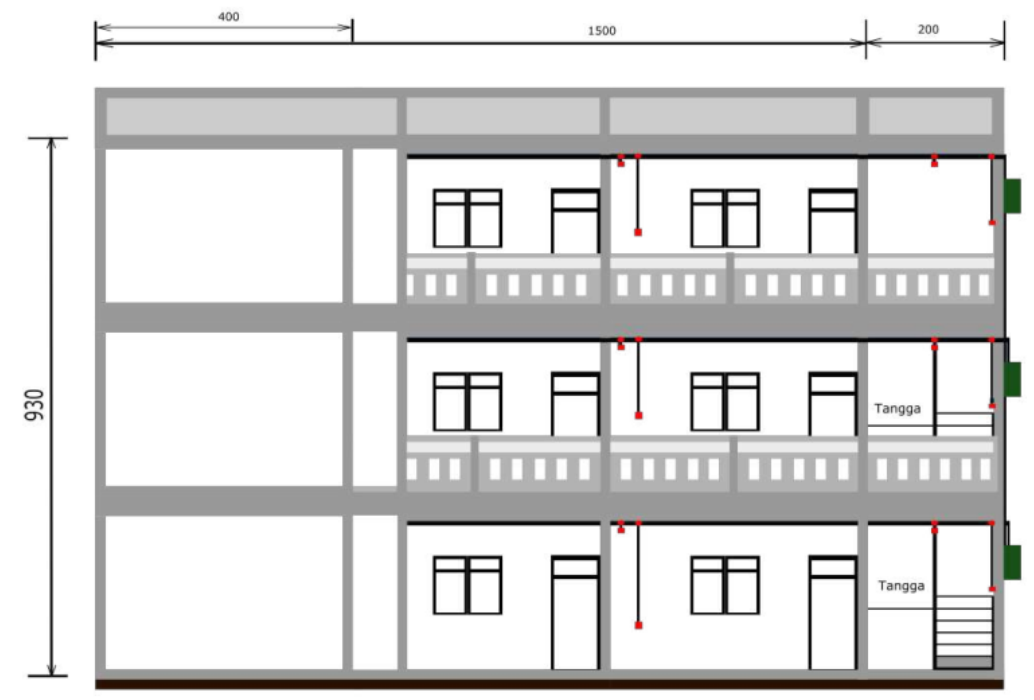

TAMPAK SAMPING

SKALA $1: 100$

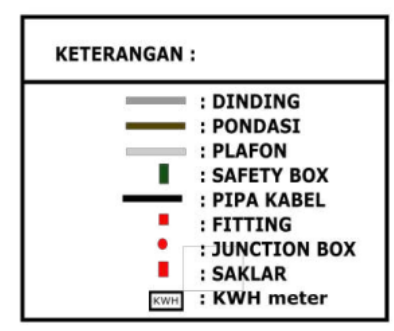

Gambar 3. Tampak Samping Bangunan Baru Ponpes STP SMP/SMA KU Sumedang

Pada gambar desain single line diagram (SLD) Pondok Pesantren STP SMP/SMA KU Sumedang yang diperlihatkan pada Gambar 5 dibawah memberikan informasi dan petunjuk pemasangan dan jenis pengaman dan penggunaan jenis kabel dan luas penampang yang digunakan. Kapasitas pembatas yang diajukan untuk pemasangan oleh PLN adalah 40A dan pengaman (MCB) untuk setiap lantai adalah $16 \mathrm{~A}$ dan jenis dan luas penampang kabel NYM 3 x 2,5 mm².

Untuk setiap informasi tentang penggunaan setiap peralatan listrik di atas dihitung berdasarkan persamaan-persamaan yang diberikan pada sub bab 2, yaitu:

1. Daya Total

Daya total dihitung berdasarkan perencanaan beban yang akan dipasang pada seluruh ruang kelas dengan rakapitulasi sebagai berikut: 
Tabel 1. Rekapitulasi Daya

\begin{tabular}{|c|c|c|c|r|}
\hline No & Peralatan & Jumlah & $\begin{array}{c}\text { Daya } \\
\text { (Watt) }\end{array}$ & $\begin{array}{c}\text { Jumlah } \\
\text { Daya } \\
\text { (Watt) }\end{array}$ \\
\hline 1. & Lampu LED & 75 & 12 & 900 \\
\hline 2. & Stop Kontak AC & 15 & 300 & 4.500 \\
\hline 3. & Stop Kontak 4 arde & 15 & 200 & 3.000 \\
\hline \multicolumn{4}{|c|}{ Total } \\
\hline
\end{tabular}

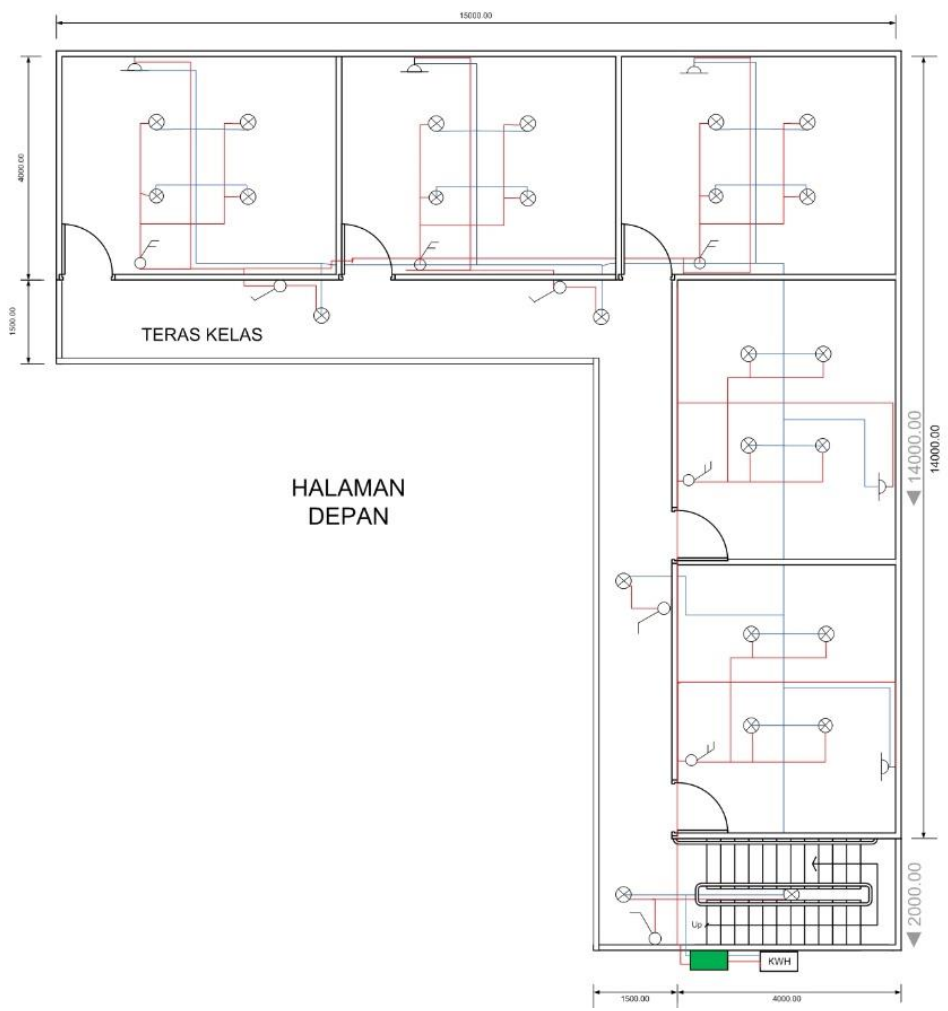

Keterangan :

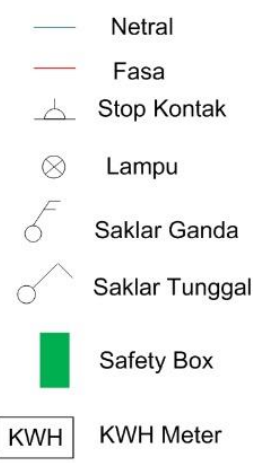

Gambar 4. Wiring Bangunan Baru Ponpes STP SMP/SMA KU Sumedang

2. Kapasitas Pengaman dan Pembatas

Dengan rekapitulasi daya pada Tabel 1, diketahui total daya perencanaan beban terpasang adalah $8,4 \mathrm{~kW}$. Jika ingin memperhitungkan faktor daya beban maka bisa mengambil cos $\varphi=0,85$. Faktor daya 0,85 ini berdasarkan ketentuan faktor daya terkecil yang diizinkan PLN, sehingga daya VA (daya semu S) perencanaan terpasang berdasarkan persamaan (1) adalah;

$$
S=\frac{8400 \mathrm{Watt}}{0,85}=9822 \mathrm{VA}
$$

Bila dibulatkan, didapatkan daya total sebesar $10 \mathrm{kVA}$. Tegangan sistem PLN diketahui adalah 220 Volt, sehingga dari daya total ini pembatas dapat dihitung berdasarkan persamaan (3), yaitu:

$$
I=\frac{S}{V}=\frac{10 k V A}{220 V}=45 \text { Amper }
$$


Dari perhitungan diperoleh arus sebesar 45 Amper, sehingga bisa memilih kapasitas pembatas MCB 40 Amper.

3. Luas Penampang Kabel

Luas penampang kabel ditetapkan berdasarkan nilai KHA kabel seperti diberikan persamaan (4) pada subbab 2.2.

$$
K H A=1,25 \times I_{n}=1,25 \times 45 A=56,25 \text { Amper }
$$

Jenis dan luas penampang kabel yang dipilih adalah NYM $3 \times 6$ mm$^{2}$ dan NYM $3 \times 2,5$ $\mathrm{mm}^{2}$ seperti terlihat dalam gambar single line diagram (SLD).

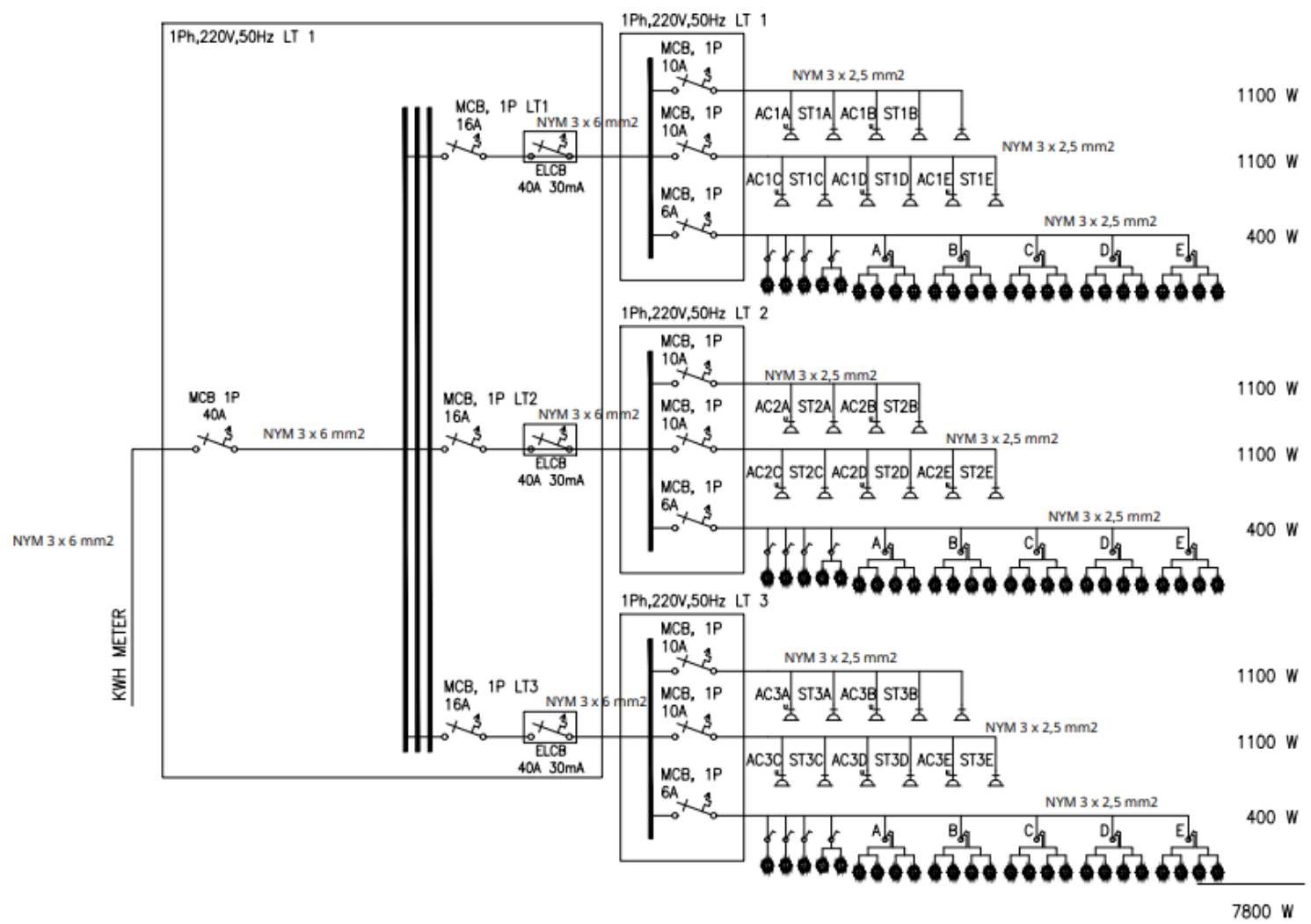

Gambar 5. Single Line Diagram (SLD) Bangunan Baru Ponpes STP SMP/SMA KU Sumedang

Beberapa dokumentasi kegiatan yang diberikan di sini adalah seperti kegiatan survey lokasi yang tampak pada Gambar 5 dan kegiatan desain gambar rencana instalasi seperti pada Gambar 6 berturut-turut berikut ini. 

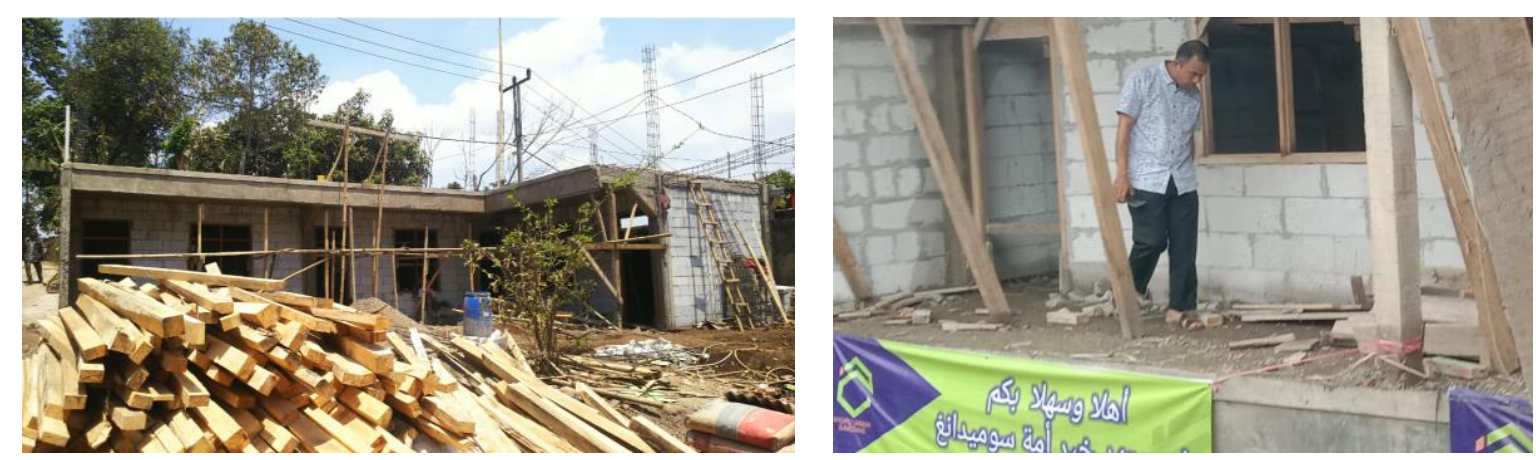

Gambar 6. Lantai 1 Bangunan Baru Ponpes STP SMP/SMA KU Sumedang

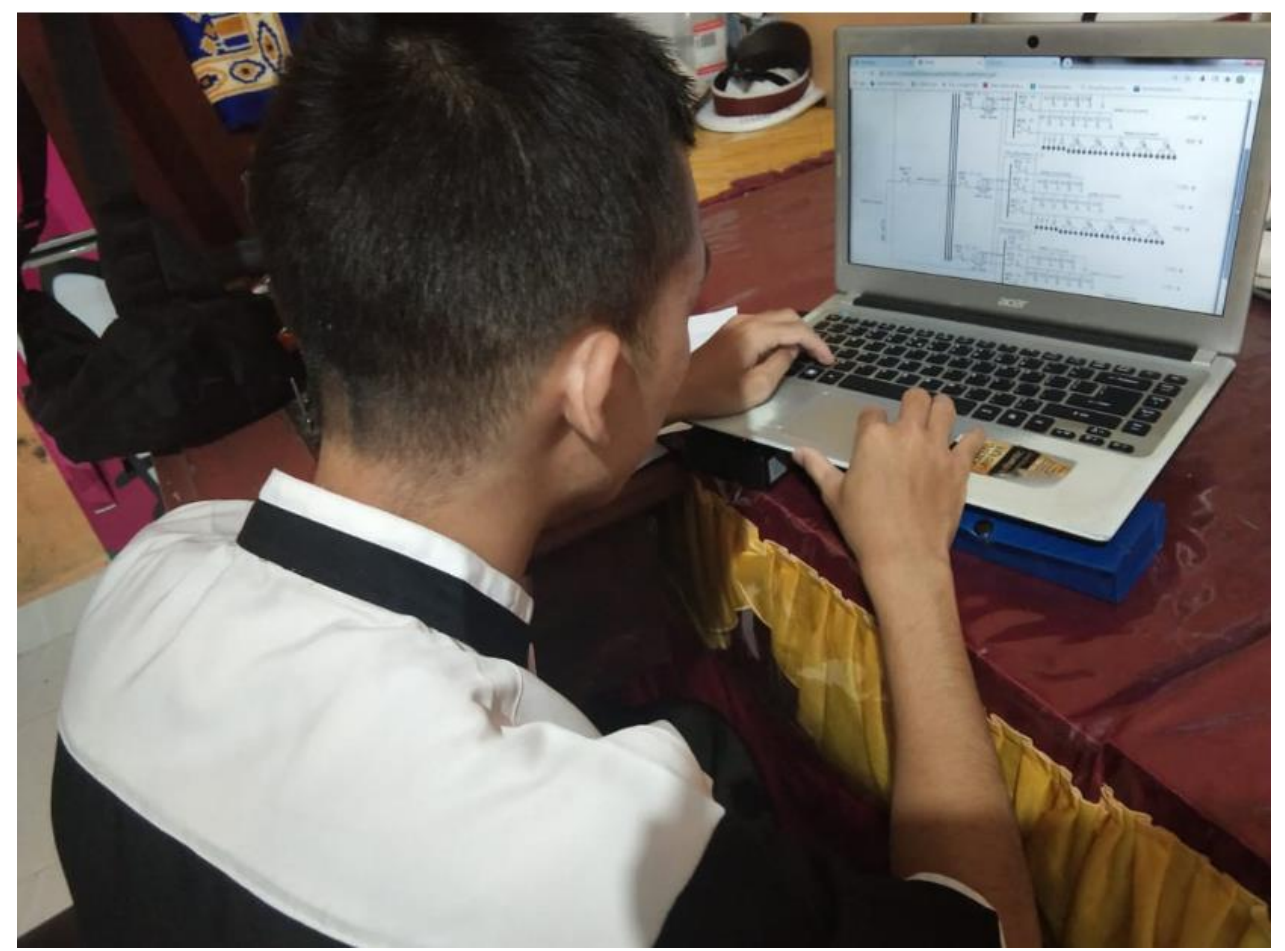

Gambar 7. Mengerjakan Desain Instalasi Listrik Bangunan Baru Ponpes STP SMP/SMA KU

\section{KESIMPULAN}

Berdasarkan hasil dan pembahasan maka dapat ditarik kesimpulan sebagai berikut:

1. Ruang kelas dengan luas $4 \times 5 \mathrm{~m}^{2}$ membutuhkan iluminasi 25 lux dengan 4 titik lampu LED dengan daya 4 x 12 watt atau setara 4 x 98 watt.

2. Total daya perencanaan beban terpasang adalah $8,4 \mathrm{~kW}$ atau $9,8 \mathrm{kVA}$ (dengan cos phi $0,85)$ dan dibulatkan menjadi $10 \mathrm{kVA}$.

3. Kapasitas pembatas MCB adalah 40 Amper, dan pengaman MCB lain bisa dilihat dalam gambar single line diagram (SLD).

4. KHA kabel adalah 56,25 Amper dan luas penampang dan jenis kabel yang dipilih adalah NYM 3 x $6 \mathrm{~mm}^{2}$ dan NYM 3 x 2,5 $\mathrm{mm}^{2}$. 


\section{SARAN}

Adapun saran yang bisa diberikan pada kegiatan ini adalah:

1. Banyak bangunan, baik rumah tinggal maupun bangunan-bangunan sosial lainnya yang dibangun tidak memenuhi standar PUIL, karena itu disarankan bagi masyarakat yang akan membangun bangunan baru dengan memperhatikan standar yang ada.

2. Lembaga Kesesuaian PUIL agar menjanlankan fungsinya untuk mengawasi bangunan yang dibangun tidak memenuhi standar PUIL.

\section{UCAPAN TERIMAKASIH}

Penulis mengucapkan terima kasih kepada LPPM Institut Teknologi PLN atas dukungan dana yang diberikan kepada team PkM sehingga kegiatan PkM ini dapat terlaksana dan juga penulis mengucapkan terima kasih kepada pengelolah STP SMP/SMA KU Sumedang atas kerjasamanya memberikan kesempatan kepada team PkM untuk melaksanakan PkM di STP SMP/SMA KU Sumedang.

\section{DAFTAR PUSTAKA}

[1] D. Haikal, "Academia.edu," [Online]. Available: https://www.academia.edu/30447876/Instalasi_Gedung_Bertingkat. [Diakses 2211 2019].

[2] "egsean.com," [Online]. Available: https://egsean.com/perencanaan-instalasi-listrik-rumah/. [Diakses 2211 2019].

[3] D. A. Ainun Widi Cahyaningrum, "scribd," [Online]. Available: https://www.scribd.com/doc/212678027/Makalah-merancang-instalasi-penerangan-gedungbertingkat-tiga. [Diakses 2411 2019].

[4] Badan Standarisasi Nasional (BSNI), Persyaratan Umum Instalasi Listrik 2011 (PUIL 2011), Badan Standarisasi Nasional (BSNI), 2011.

[5] M. Ir. Wahyudi Sarimun N, Diktat Instalasi Listrik, -: -, 2011. 